\title{
Efficiency of Using Natural Zeolites in Cultivation of African Catfish
}

\author{
Tatiana Shlenkina, Elena Romanova*, Vasily Romanov and Vaselina Lyubomirova \\ Ulyanovsk State Agrarian University named after P.A. Stolypin, Ulyanovsk, 432017, Russia
}

\begin{abstract}
The article represents the results of studies in zeolite use in fish feeding. The influence of zeolites on the exterior and interior characteristics of African catfish grown in high-technological industrial aquaculture was evaluated. Zeolites were introduced into fish feed in the amount of $3 \%$ and $5 \%$. The use of zeolites in feeding of African catfish has had a positive impact on the growth, exterior and interior indicators of fish. In five-month-old catfish, when using zeolites, the average daily growth increased by $4.15 \mathrm{~g}$ (with $3 \%$ addition of zeolites) and by $4.68 \mathrm{~g}$ (with $5 \%$ addition of zeolites), compared to fish that did not receive zeolites. In the experimental groups, there was also an increase in absolute growth by 124.4 g-with $3 \%$ addition of zeolites and $140.2 \mathrm{~g}$-with $5 \%$ addition of zeolites. The commercial weight of fish using zeolites increased by $24.05 \%$ and $35.52 \%$, respectively. The results show that when growing commercial fish, the use of zeolites in the feed composition fastens its growth and significantly reduces feed costs.
\end{abstract}

\section{Introduction}

Fish is one of the main food products of population of our planet. Nowadays, natural fish resources, with increasing amounts of fishing, do not have time to be replenished. In this regard, there is a need to increase the extent of managed reproduction of fish resources. To solve this problem, it is necessary to develop aquaculture. Aquaculture is understood as breeding, maintenance and cultivation of fish in natural and artificial reservoirs, on marine plantations, in industrial aquaculture, including in recirculating aquaculture systems (RAS).

Feed composition plays an important role in cultivation of fish in industrial aquaculture [1-4]. In order to increase productivity and improve the quality of products obtained, it is necessary to organize a fullfledged feeding, which would not only ensure the rapid growth of fish, but also enrich it with proteins, fats and carbohydrates, vitamins, amino acids and minerals [5-7]. Zeolites can become suppliers of mineral substances that stimulate growth. Zeolites are widely used in agriculture in Russia and other countries [7-10]. They are used as sorbents $[3,5,7,10,11]$, which have proven themselves well in animal husbandry, poultry farming, crop production and other agricultural sectors. In recent years, zeolites have also been tested in fish farming. Cases of their use in cultivation of European sea bass, rainbow trout and many other fish species were described [3, 1113, 14]; the use of zeolites for cleaning the aquatic environment from various pollutants is no less important [11-17].
In fish farming, zeolites were also used as sorbents for water purification. Zeolites in reservoir adsorb potentially pathogenic and pathogenic microbiota, which prevents fish diseases, improves blood circulation, and increases fish resistance and growth rate [2]. In general, the use of zeolites improves the sanitary parameters of the fish habitat.

Table 1. Mineral and chemical composition of zeolitecontaining rocks of Ulyanovsk field

\begin{tabular}{|c|c|c|c|c|c|}
\hline \multicolumn{4}{|c|}{ Name of components } & \multicolumn{2}{|c|}{ Content } \\
\hline \multicolumn{4}{|c|}{$\begin{array}{c}\text { Минералы ( \%, wt) } \\
\text { Clinoptilolites (zeolite) }\end{array}$} & \multicolumn{2}{|c|}{18} \\
\hline \multicolumn{4}{|c|}{ Opal-cristobalite } & \multicolumn{2}{|c|}{31} \\
\hline \multicolumn{4}{|c|}{ Calcite } & \multicolumn{2}{|c|}{19} \\
\hline \multicolumn{4}{|c|}{ Clay minerals of montmorillonite } & \multicolumn{2}{|c|}{18} \\
\hline \multicolumn{4}{|c|}{ Hydromicas } & \multicolumn{2}{|c|}{6} \\
\hline \multicolumn{4}{|c|}{ Cilica } & \multicolumn{2}{|c|}{8} \\
\hline \multicolumn{2}{|c|}{ Oxides for air-dry quantity $(\%, w t)$} & \multicolumn{4}{|c|}{ Elements (mg/kg) } \\
\hline $\mathrm{SiO}_{2}$ & 56.8 & $\mathrm{Be}$ & 1.6 & $\mathrm{Ag}$ & 0.15 \\
\hline $\mathrm{TiO}_{2}$ & 0.30 & As & 25 & $\mathrm{Zn}$ & 90 \\
\hline $\mathrm{Al}_{2} \mathrm{O}_{3}$ & 3.12 & $\mathrm{~F}$ & 310 & $\mathrm{Co}$ & 11 \\
\hline $\mathrm{Fe}_{2} \mathrm{O}_{3}$ total & 2.27 & $\mathrm{Sc}$ & $<10$ & $\mathrm{Ni}$ & 34 \\
\hline $\mathrm{MnO}$ & $0.00-0.01$ & $\mathrm{~Pb}$ & $<500$ & $\mathrm{Zr}$ & 90 \\
\hline $\mathrm{CaO}$ & 13.24 & $\mathrm{Mn}$ & 360 & $\mathrm{Cr}$ & 63 \\
\hline $\mathrm{MgO}$ & 1.87 & $\mathrm{P}$ & 11 & $\mathrm{Sr}$ & 440 \\
\hline $\mathrm{Na}_{2} \mathrm{O}$ & 0.12 & $\mathrm{Sn}$ & 1.3 & $\mathrm{Ba}$ & 330 \\
\hline $\mathrm{K}_{2} \mathrm{O}$ & 1.44 & $\mathrm{Nb}$ & 10 & $\mathrm{Hg}$ & 0.06 \\
\hline $\mathrm{P}_{2} \mathrm{O}_{5}$ & 0.16 & $\mathrm{Ca}$ & 6 & $\mathrm{~V}$ & 18 \\
\hline $\mathrm{CO}_{2}$ & 10.27 & $\mathrm{~V}$ & 79 & $\mathrm{Vb}$ & 1.6 \\
\hline $\mathrm{H}_{2} \mathrm{O}$ & 7.16 & $\mathrm{Li}$ & 32 & $\mathrm{~B}$ & 44 \\
\hline The amount & 99.83 & $\mathrm{Cu}$ & 14 & \multirow{2}{*}{$\mathrm{Ge}$} & \multirow{2}{*}{$<2$} \\
\hline $\mathrm{SiO}_{2}$ amorphous & 27.13 & $\mathrm{Cd}$ & $<1$ & & \\
\hline
\end{tabular}

Te, Sb, Ta, Tl, W, Jn, Bi - not detected.

\footnotetext{
* Corresponding author: vvr-emr@yandex.ru
} 
In our research, we used zeolites from the Ulyanovsk region deposit when feeding fish.

The Ulyanovsk region has large reserves of mineral resources, including highly siliceous rocks (diatomites, flasks, berg-meal, zeolites). Zeolite tuffs of various deposits can be distinguished by their color, strength, and physical and chemical properties. The composition of zeolite of the Ulyanovsk Region deposit includes up to 40 mineral elements (table 1).

Unlike volcanic zeolite rocks, the microelement composition of sedimentary zeolite has low content of beryllium, lead, gallium, copper, zirconium, strontium, barium, yttrium, ytterbium, tin, arsenic and is characterized by an increased level of vanadium, nickel, lithium, manganese, boron and chromium. At the same time, the level of toxic elements is within the norm.

The aim of our research was to evaluate the effectiveness of use of natural zeolites from the Ulyanovsk deposit in feeding African catfish.

\section{Materials and methods}

To conduct the experiment, three groups of 15 individuals each, aged 4 months, were formed. The experiment lasted 60 days. The first group received the basic diet (BD), the second group received $3 \%$ $(\mathrm{BD}+3 \%)$ of zeolite in addition to the basic diet, and the third group received $5 \%(\mathrm{BD}+5 \%)$ of zeolite.

The fish were kept in pools equipped with filters on quartz sand. The volume of the pools is $3.8 \mathrm{~m} 3$, the depth is $85 \mathrm{~cm}$. The oxygen content is $70 \%$. The daily water change was at least $25 \%$. We used extruded feed from the company LimKorm for feeding.

Morphometric studies were carried out according to the generally accepted methodology. Measurements were carried out using a caliper with an accuracy of $1 \mathrm{~mm}$. The fatness coefficient was calculated according to the formula proposed by Fulton. Fatness coefficient (Ac) - characterizes the fatness, "fleshiness" of fish. The fatness coefficient is defined as the ratio of mass to body length: according to the formula of T. Fulton,

$$
\mathrm{K}_{\mathrm{y}}(\phi)=\frac{\mathrm{P} \cdot 100}{\mathrm{~L}^{3}}
$$

where $\mathrm{P}$ is the fish mass $(\mathrm{g}), \mathrm{L}$ is the length $(\mathrm{cm})$ in carp, salmon to the end of the scaly cover, in sturgeon and other species the entire length or to the end of the caudal fin lappet .

To characterize the intensity of growth, we used the indicators of absolute, relative and average daily growth.

The absolute average daily increase in live weight for a certain period is determined by the formula:

$$
A=\frac{W_{1}-W_{0}}{t}
$$

where $\mathrm{A}$ is the average daily increase in live weight (g) or measurements $(\mathrm{cm})$; W0 is the initial mass $(\mathrm{kg})$ of the animal or the initial value of measurement $(\mathrm{cm})$; W1 is the live weight of animal (or the value of measurement) at the end of the period; $t$ is the time of the experiment in days.

Relative growth is the value of the growth rate of animal, expressed in percent, calculated by the formula:

$$
K=\frac{W_{1}-W_{0}}{W_{0}} \cdot 100 \%
$$

where W0 is the initial mass $(\mathrm{kg})$ of the animal or the initial measurement value $(\mathrm{cm})$; W1 is the live mass of the animal or the measurement value at the end of the period.

\section{Results}

The dynamics of morphometric characteristics in catfish depending on the content of zeolites in used feed was studied. The analysis of obtained results showed that the content of zeolites in the feed influenced the growth rate of catfish. In particular, such exterior indicators as zoological and commercial length and body weight were informative. Higher rates were observed in the experimental group, in which the addition of zeolites reached $5 \%$ of the feed weight.

The research results on the effectiveness of zeolites use in feed for such fish species as the African clary catfish are shown in Tables 2, 3 .

During the research, it was found that the introduction of a zeolite-containing additive in the diet of clary catfish had a positive effect on the external indicators.

Zoological length is the length from the tip of the head ("top of the snout") to the end of the longest blade of the caudal fin. The zoological length throughout the experiment in the control group was lower compared to the second and third experimental groups (Figure 1).

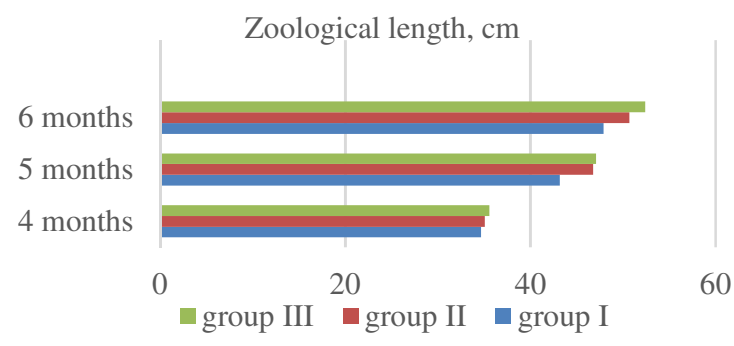

Fig. 1. Zoological length of catfish

During the first month of the experiment, the zoological length in the second experimental group was $8.33 \%$ greater than in the first, and in the third, compared to the control, by $9.03 \%$. The next 30 days, this difference was 5.84 and $9.39 \%$, respectively. During 60 days of the experiment, the fish in the control group increased their length by $13.2 \mathrm{~cm}$, the fish in the second experimental group grew by $15.6 \mathrm{~cm}$, and in the third experimental group-by $16.8 \mathrm{~cm}$. Thus, the introduction of zeolite into the diet contributed to the rapid growth of individuals.

Fishing length is the length from the tip of the head ("top of the snout") to the beginning of the caudal fin. Studying this indicator, it can be noted that during the experimental period, it was higher in the experimental groups than in the control group, both at the age of 5 months and at the age of 6 months (Figure 2). 


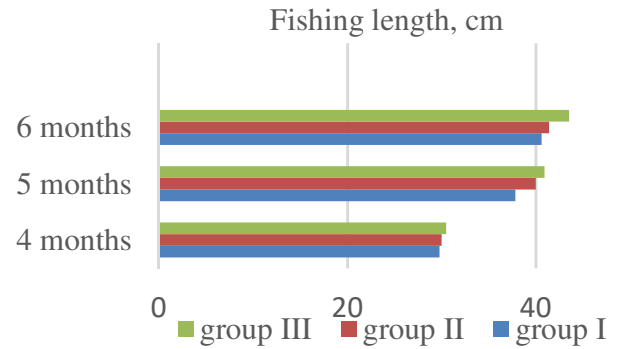

Fig. 2. Fishing length

These differences were 5.82 and $8.22 \%$, and 1.97 and $7.14 \%$, respectively. Thus, the additive in the amount of $5 \%$ played a more pronounced positive role than the additive $3 \%$.

An important exterior indicator is the length of the carcass. On the basis of this indicator, you can judge the commercial qualities of fish. For 60 days of the experimental period, the length of clary catfish carcass in the first experimental group increased by $8.65 \mathrm{~cm}$, in the second experimental group by $9.56 \mathrm{~cm}$, in the third by $11.07 \mathrm{~cm}$ (Figure 3).

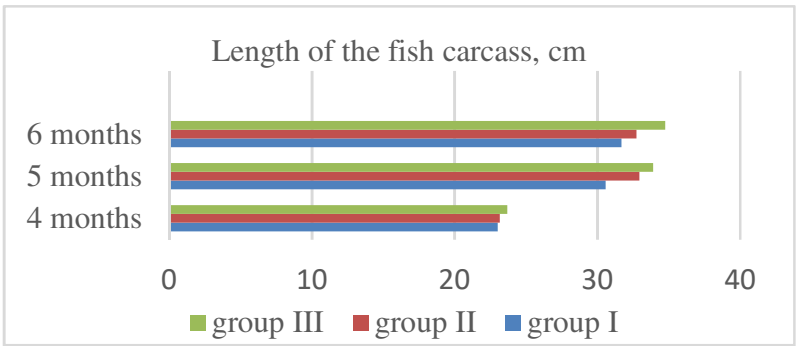

Fig 3. Length of the fish carcass

With age, African catfish change the proportions of the head and body. Increasing the length of the body and reducing the size of the head, make it easier for the fish to move. The most stable indicators were: the length of the head, the width of the head and the height of the caudal stem. Thus, when comparing these indicators, no significant differences were observed.

Table 2. Exterior parameters of clary catfish

\begin{tabular}{|c|c|c|c|c|c|c|c|c|c|}
\hline \multirow{3}{*}{ Indicators } & \multicolumn{9}{|c|}{ Age } \\
\cline { 2 - 9 } & \multicolumn{3}{|c|}{ 4 months } & \multicolumn{3}{c|}{ G months } & \multicolumn{3}{c|}{ 6 months } \\
\cline { 2 - 9 } & \multicolumn{3}{|c|}{ Groups } & \multicolumn{3}{c|}{} \\
\cline { 2 - 9 } & I group & II group & III group & I group & II group & III group & I group & II group & III group \\
\hline Zoological length, cm & $34.7 \pm 3.7$ & $35.1 \pm 2.6$ & $35.6 \pm 3.4$ & $43.2 \pm 3.9$ & $46.8 \pm 1.8$ & $47.1 \pm 0.6$ & $47.9 \pm 0.5$ & $50.7 \pm 1.3$ & $52.4 \pm 1.0$ \\
\hline Fishing length, cm & $29.8 \pm 1.6$ & $30.0 \pm 3.56$ & $30.5 \pm 2.5$ & $37.8 \pm 0.7$ & $40.0 \pm 1.1$ & $40.9 \pm 0.9$ & $40.6 \pm 0.5$ & $41.4 \pm 0.7$ & $43.5 \pm 0.6$ \\
\hline Length of the fish carcass, cm & $23.03 \pm 1.4$ & $23.17 \pm 1.9$ & $23.69 \pm 2.3$ & $30.57 \pm 1.6$ & $32.95 \pm 3.3$ & $33.9 \pm 3.2$ & $31.68 \pm 0.6$ & $32.73 \pm 1.3$ & $34.76 \pm 1.9$ \\
\hline Head length, cm & $6.77 \pm 3.2$ & $6.83 \pm 1.4$ & $6.81 \pm 0.8$ & $7.23 \pm 0.7$ & $7.05 \pm 4.5$ & $7.0 \pm 0.5$ & $8.92 \pm 0.7$ & $8.67 \pm 1.1$ & $8.74 \pm 0.4$ \\
\hline Head width, cm & $5.56 \pm 0.8$ & $5.72 \pm 1.3$ & $5.64 \pm 0.8$ & $6.64 \pm 0.4$ & $6.48 \pm 0.5$ & $6.48 \pm 0.5$ & $7.09 \pm 0.5$ & $6.99 \pm 0.5$ & $7.01 \pm 0.6$ \\
\hline Body height, cm & $4.91 \pm 0.6$ & $4.95 \pm 0.8$ & $4.91 \pm 0.7$ & $5.3 \pm 0.5$ & $5.5 \pm 0.5$ & $5.45 \pm 0.7$ & $6.2 \pm 0.6$ & $7.1 \pm 0.6$ & $7.4 \pm 0.6$ \\
\hline Length of the caudal stem, cm & $4.9 \pm 0.3$ & $5.1 \pm 0.6$ & $5.1 \pm 0.7$ & $5.4 \pm 0.7$ & $6.8 \pm 0.7$ & $6.2 \pm 0.6$ & $7.3 \pm 0.6$ & $9.3 \pm 0.3$ & $8.9 \pm 0.5$ \\
\hline Height of the caudal stem, cm & $2.87 \pm 0.4$ & $2.91 \pm 0.5$ & $2.97 \pm 0.6$ & $3.61 \pm 0.4$ & $3.78 \pm 0.6$ & $3.69 \pm 0.8$ & $4.41 \pm 0.4$ & $4.25 \pm 0.7$ & $4.43 \pm 0.4$ \\
\hline Weight, g & $510.3 \pm 18.8$ & $520.9 \pm 22.6$ & $515.1 \pm 24.3$ & $635 \pm 6.1$ & $770 \pm 50.3$ & $780 \pm 39.7$ & $710 \pm 13.58$ & $850 \pm 26.36$ & $900 \pm 7.15$ \\
\hline
\end{tabular}

Based on the study of exterior indicators, we can conclude that the addition to the main diet of zeolites in the amount of $5 \%$ is the most optimal. As a result of the introduction of zeolite in an amount of $5 \%$ to the main diet, such indicators as zoological length, commercial length and carcass length increase in comparison with the control group. There were no significant differences between the experimental groups.

During the studies, it was found that the introduction of a feed supplement into the diet had a positive effect on body weight (Figure 4, Table 2).

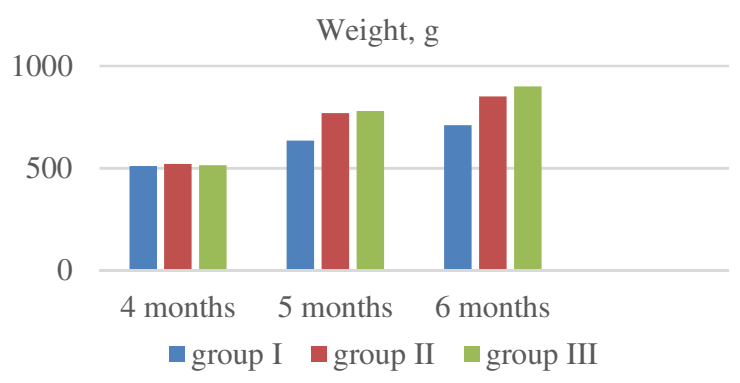

Fig. 4. Fish weight
The highest indicators of the average body weight of clary catfish were typical for the 2 and 3 experimental groups, where zeolite was introduced in addition to the main diet. In the beginning of the experiment, the average weight of fish in the experimental and experimental groups did not have significant differences.

At the age of 5 months, the weight of fish in the second experimental group, which had $3 \%$ of zeolites added to the feed, was $21.26 \%$ higher than in the control group. In the third group, where the zeolite additive comprised $5 \%$, the differences between the control and experimental groups were $22.83 \%$.

At the age of 6 months, these differences were even more vivid and amounted to 19.72 and $26.76 \%$, respectively. Thus, the final weight of fish in the group receiving $3 \%$ zeolite additive was $850 \pm 26.36 \mathrm{~g}$, in the third group receiving $5 \%$ zeolite additive was $900 \pm 7.15 \mathrm{~g}$.

The research results showed that the addition of zeolites in fish feed had a positive effect on the exterior performance of African catfish.

The fatness coefficient (FC) is a variable value. It depends on the age of the fish, its size, type and breed, as well as on the stage of maturity of the sexual products. In our experiments, the fatness coefficient ranged from 
1.06-1.20. The Clary catfish of the second experimental group had a higher fatness coefficient. In this group, high fatness can be explained by more efficient use of feed.

The largest absolute increase in clary catfish was observed in the period from 4 to 5 months (Table 3 ). Thus, the absolute increase in the control group was $124.7 \mathrm{~g}$, in the second $249.1 \mathrm{~g}$ and in the third $264.9 \mathrm{~g}$. Thus, with $3 \%$ addition of zeolites to feed, the absolute increase was 1.2 times, and with $5 \%$ addition of zeolites to feed, the absolute increase was 2.12 times greater than in the control group.

At the age of 6 months, the differences between the control and experimental groups were even more marked (Table 3).

Table 3. Growth rate of clary catfish

\begin{tabular}{|c|c|c|c|c|c|c|}
\hline \multirow[b]{4}{*}{ Indicators } & \multicolumn{6}{|c|}{ Age } \\
\hline & \multicolumn{3}{|c|}{5 months } & \multicolumn{3}{|c|}{6 months } \\
\hline & \multicolumn{6}{|c|}{ Groups } \\
\hline & ن̈ & 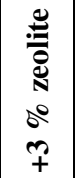 & 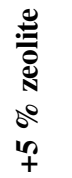 & 宊 & 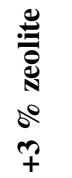 & 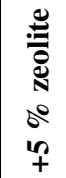 \\
\hline $\begin{array}{c}\text { Fatness ratio } \\
\text { (by Fulton) }\end{array}$ & 1.17 & 1.20 & 1.14 & 1.06 & 1.19 & 1.09 \\
\hline $\begin{array}{l}\text { Average daily } \\
\text { growth, } g\end{array}$ & 4.15 & 8.3 & 8.83 & 2.5 & 2.66 & 4.0 \\
\hline Absolute increase, $\mathrm{g}$ & 124.7 & 249.1 & 264.9 & 75 & 80 & 120 \\
\hline $\begin{array}{l}\text { Relative growth } \\
\text { rate, } \%\end{array}$ & 21.77 & 38.59 & 40.91 & 9.87 & 11.15 & 14.28 \\
\hline
\end{tabular}

The average daily increase, as well as the absolute increase, was higher in the period from 4 to 5 months, rather than from 5 to 6 months. There were no significant differences between the experimental groups.

The relative growth rates in the fish of experimental groups were also higher at the age of 5 months.

\section{Discussion}

Changes in the exterior parameters of clary catfish grown using zeolite-containing rock in diets in the amount of $5 \%$ contributed to an increase in such indicators as zoological length, commercial length and carcass length.

As a result of the experiment, it was established that the addition of the studied feed additive to fish diet had a positive effect on the increase in the mass of individuals. So the final weight in the second experimental group was $850 \pm 26.36 \mathrm{~g}$, in the third group it was $900 \pm 7.15 \mathrm{~g}$.

Our results are consistent with the data of other researchers [12, 15] on the positive effect of zeolite additives on the growth, development and physiological state of many fish species [11-15].

The use of zeolite-containing feed in fish farming, not only helps to increase the growth rate of fish, but also contributes to the cleaning of their habitat $[14,16$, $19]$.
Zeolite in the composition of feed can be evaluated as a factor that stimulates growth, development and intensity of metabolism. Clary catfish use feed more effectively, grow faster, acquire increased resistance to diseases, become more viable, and are less exposed to digestive disorders.

The results of our research have shown the feasibility of using zeolites in the amount of $5 \%$.

Our results showed that the use of zeolites in the feeding diets of African clary catfish intensified the process of growing commercial fish.

\section{Conclusion}

In the conditions of modern civilization, when the demand for fish products is constantly growing all over the world and the requirements for its quality are becoming stricter, the development of year-round hightech industrial aquaculture plays an important role. The use of intensive fish farming technologies allows controlling the parameters of the environment, but excludes the availability of natural food. Therefore, it is so important to properly compose a fish feeding diet.

Artificial diets, balanced by the main elements of nutrition, for all their effectiveness, do not fully meet the physiological needs of young and mature individuals of different ages.

This is due to the fact that natural food contains a wider set of biologically active components that are regulators of many metabolic processes in the body of fish.

Of particular importance is the introduction of feed probiotics, adaptogens [19, 20] and minerals necessary for fish metabolism into artificial compound feeds. In our research, we used zeolites as mineral substances. The results of our research have shown that the use of zeolites in the artificial cultivation of fish in high-tech aquaculture has a significant growth-stimulating effect.

\section{Acknowledgments}

The Russian Foundation for Basic Research has supported our study with the grant No. 18-416-730005.

\section{References}

1. G. Baeverfjord, B. Hatlen, T. Åsgård et al., Mineral nutrition and bone health in salmonids, Rev. in aquacult., 11(3), 740-765 (2019)

2. Jain S.K. Protective role of zeolite on short- and long-term lead toxicity in the teleost fish heteropneustes fossilis, Chemosph., 39(2), 247-251 (1999)

3. H.A. Aly, M.M. Abdel-Rahim, G.R. Sallam, A.M. Lotfy, B.S. Abdelaty, Use of natural zeolites as a detoxifier of heavy metals in water and the flesh of reared european seabass dicentrarchus labrax, Ribarstvo, 78(3), 121-132 (2020) 
4. Z. Ghasemi, I. Sourinejad, H. Kazemian, S. Rohani, Application of zeolites in aquaculture industry: a review, Rev. in Aquacult., 10(1), 75-95 (2018)

5. L. Dediu, A. Docan, Iu. Grecu, "Comparison of ammonia removal in recirculating aquaculture system using nitrifying biofilter and zeolite", 19th Int. Sci. Geoconf. (SGEM 2019) (2019), pp. 3-10

6. A. Paritova, N. Biltebayevna, G. Kuzembekova, Z. Valieva, D. Sarybaeva, "The chemical composition and nutritional value of fish meat while using as a feed additive zeolite of chankanay origin", Res. for Rural Develop., ser. Res. for Rural Develop. 2011, Annual 17th Int. Sci. Conf. Proc. (2011), pp. 163-167

7. Z. Shokouh Saljoghi, Gh. Rafiee, A. Malekpour, A. Shokooh Saljooghi, O. Safari, Application of modified bentonites (smb and atb) for decreasing the environmental effects of phosphate and sulphate anions existing in ras, J. of Envir. Stud., 38(61), 31-40 (2012)

8. J. Sanchez, N. Marino, M.C. Vaquero, J. Ansorena, I. Legorburu, Metal pollution by old lead-zinc mines in urumea river valley (basque country, spain). Soil, biota and sediment, Water, air, \& soil pollut., 107(1-4), 303-319 (1998)

9. F.A. Mumpton, La roca magica: uses of natural zeolites in agriculture and industry, Proc. of the Nat. Acad. of Sci. of the USA, 96(7), 3463-3470 (1999)

10. N. Eroglu, M. Emekci, C.G. Athanassiou, Applications of natural zeolites on agriculture and food production, J. of the Sci. of Food and Agricult., 97(11), 3487-3499 (2017)

11. K. Ramesh, A.K. Biswas, A.S. Rao, D.D. Reddy, Zeolites and their potential uses in agriculture, Advan. in Agron., 113, 215-236 (2011)

12. A. Paritova, N. Sarsembayeva, G. Kuzembekova, A. Abzhalieva, B. Łozowicka, P. Kaczyński, A. Maulanov, The influence of Chankanay zeolites as feed additives on the chemical, biochemical and histological profile of the rainbow trout (Oncorhynchus mykiss), J. of aquacult, Res. and develop., 5(A.1), 205 (2014)
13. V.V. Naumova, D.A. Kiryanov, E.V. Sveshnikova, A.N. Smirnova, The technology of raising rainbow trout on the farms, Res. J. of pharmac., biol. and chem. Sci., 10(3), 206-209 (2019)

14. O. Baturevych, T. Bersan, Productive and economic efficiency of rearing table carp with the use of nontraditional feed additives, Fisher. Sci. of Ukraine, 2(52), 86-96 (2020)

15. A.E. Paritova, N.B. Sarsembayeva, B. Buralhiev, A.E. Slyamova, An experimental study of the effect of natural zeolite of chankanay deposits on fishbreeding and biological and hematological parameters of the body of fish, Glob. veter., 11(3), 348-351 (2013)

16. N. Abrosimova, E. Abrosimova, Y. Kokhanov, T. Arutyunyan, K. Abrosimova, Prospects for using mineral resources of southern russia in aquaculture, E3S Web of Conf., 8, 09001 (2020)

17. Z. Saljoghi, Gh. Rafiee, A. Malekpour, A. Shokooh Saljooghi, O. Safari, Application of modified bentonites for decreasing the environmental effects of phosphate and sulphate anions existing in ras shokouh, J. of Envir. Stud., 38(61), 31-40 (2012)

18. E. Solgi, F. Beigzadeh-Shahraki, Accumulation and human health risk of heavy metals in cultured rainbow trout (Oncorhynchus mykiss) form different fish farms of eight cities of chaharmahal and bakhtiari province, Iran, Thalassas, 35(1), 305-317 (2019)

19. E.M. Romanova, V.V. Romanov, V.N. Lyubomirova, L.A. Shadyeva, T.M. Shlenkina, Increase in nonspecific resistance of catfish (clarias gariepinus) in industrial aquaculture, BIO Web of Conf., 17, 00122 (2020)

20. E.M. Romanova, V.V. Romanov, V.N. Lyubomirova, L.A. Shadyeva, T.M. Shlenkina, Vectors for the development of high-tech industrial aquaculture, BIO Web of Conf., 27, 00132 (2020)

21. A.N. Kanidyev, Efficiency of adding natural zeolite (klinoktilolite) to the feed of trout ration, VNIIPRH, 45, 178-184 (1985) 